Ghanem M., Albanna R., Hage R., and Hamzeh F. (2019). "Comparing Lean Management Principles and Evolutionary Design in Nature" In: Proc. $27^{\text {th }}$ Annual Conference of the International. Group for Lean Construction (IGLC), Pasquire C. and Hamzeh F.R. (ed.), Dublin, Ireland, pp. 573-582. DOI: https://doi.org/10.24928/2019/0229. Available at: <www.iglc.net>.

\title{
COMPARING LEAN MANAGEMENT PRINCIPLES AND EVOLUTIONARY DESIGN IN NATURE
}

\author{
Malek Ghanem¹, Rania Albanna ${ }^{2}$, Ralph I. Hage ${ }^{3}$, and Farook R. Hamzeh ${ }^{4}$
}

\begin{abstract}
Evolutionary design is defined as a gradual process in which something changes into a different and usually more complex or better form. This process is apparent in nature where it is evolving towards the optimum solution. Lean is defined as a philosophy that aims at eliminating waste in production processes without compromising value. The two concepts appear in the literature as independent with little attempts to study a possible relation between them. The purpose of this paper is to explore synergies between the two seemingly distinct systems. This is performed by studying each notion on its own through breaking it down to its dynamic functional systems, and comparing the functions of each against one another. Findings reveal that the development of lean since its inception is comparable to the natural mechanisms of evolutionary design in nature. Findings suggest that lean is the natural course of evolution of construction management systems towards more optimal systems.
\end{abstract}

\section{KEYWORDS}

Lean construction, evolutionary design, nature, workflow, optimization, design science.

\section{INTRODUCTION}

Project management in general has been practiced since the establishment of humanity. From the first human settler tents in the heart of the African continent, to the Stonehenge monument in England, it helped -and continues to help- provide an environment which enables people to work together to reach a mutual objective. This long existence is proven by massive successfully built ancient projects such as The Pyramids of Giza, the Great Wall of China, and the Coliseum, among others. These enormous projects required

1 Graduate Student, Civil and Environmental Engineering Department, American University of Beirut, Beirut Riad El-Solh 1107 2020, Lebanon, mng08@ mail.aub.edu

2 Graduate Student, Civil and Environmental Engineering Department, American University of Beirut, Beirut Riad El-Solh 1107 2020, Lebanon, rma138@mail.aub.edu

3 Graduate Student, Civil and Environmental Engineering Department, American University of Beirut, Beirut Riad El-Solh 1107 2020, Lebanon, rih16@ mail.aub.edu

4 Associate Professor, Civil and Environmental Engineering Department, University of Alberta, Canada, hamzeh@ualberta.ca 
innovative planning and detailed execution, accompanied with large workforce and scope, and many years of execution. In the world of today, where societies have built their own grand and complex structures such as the Empire State building, Burj Khalifa, and the Eiffel Tower, there has been a vast increase in complexity in construction management as construction management has evolved since humans first discovered how to build shelter.

\section{LITERATURE REVIEW}

\section{Evolution of CONSTRUCTION MANAGEMENT}

Unfortunately, there are only a few instances of documentation that show the construction strategies and techniques that existed in the far past. This scarce information is thought to be caused by various reasons such as that upper-classes of society focused more on the final structure than the construction aspect, and most importantly, craftsmen kept execution details secret among their tribes to preserve their specialization (Symour and Hussein 2014).

Throughout history, man has been working on improving and refining practices of project management until reaching the advanced systems known nowadays (Symour and Hussein 2014). The use of systematic project management techniques and tools to complex projects started around half a century ago. Prior to the 1960s, project management was moving from craft system to human relations administration. This was aided by technological advancement that helped in shortening project schedules. For instance, vehicles helped in resource transportation, telephones increased in the speed of communication, etc. Besides, the Gantt Chart was invented, and job specification was spread which became a basis for Work Breakdown Structure (WBS) later on (Kwak 2003).

Then, in the late 1950s until late 1970s, significant technology advancement was used to develop new project managing techniques and tools. For instance, Xerox invented the first paper copier, which helped mainly in documentation. Moreover, computer systems, programming languages, and the first email software were introduced in this era. In addition, some major project management tools were presented as well, such as CPM/PERT, Work Breakdown Structure (WBS), Material Requirement Planning (MRP), etc. Then in the 1980s, as a part of technology advancement, a revolution in Information Technology (IT) was observed. This uprising shifted managers from using mainframe computers that are not easy to use, into multitasking personal computers, which increased the efficiency and helped in managing large complicated projects. Besides, Internet in the mid-80s helped researchers and developers, and Ethernet technology became more commonly used (Kwak 2003). Moreover, an important management philosophy was introduced, the Theory of Constraints (TOC) (Symour and Hussein 2014).

In the 1990s, technology continued to develop, where internet had a major role in facilitating organizations' business and management, increasing their productivity and efficiency (Symour and Hussein 2014). Moreover, after having all these advanced tools that made complex project management much simpler, managers and researchers were thinking of new and updated concepts and strategies rather than tools. The aim was to reduce waste without affecting value. This was the main goal of what is called Lean Construction. Lean Construction has its origin from Lean Production System that was developed by Toyota that was led by Engineer Taiichi Ohno (Howell 1999). Lean theories 
were applied to construction at first by Glenn Ballard, Gregory Howell, and Lauri Koskela, and are still in continuous evolution. More importantly though, is how one initially approaches this new management system - and the correct way of doing so can be characterized in the following section by a quote from one of the most brilliant minds of recent history, Albert Einstein, when he says, "Fundamental ideas play the most essential role in forming a physical theory. Books on physics are full of complicated mathematical formulae. But thoughts and ideas, not formulae, are the beginning of every physical theory. The ideas must later take the mathematical form of a quantitative theory, to make possible the comparison with experiment" (Einstein and Infeld 1938).

The fact that Lean management started with efforts directed at the Toyota vehicular manufacturing process lead to many managerial features accredited by Toyota Production System (TPS) such as just-in-time inventory organization technique. This meant requiring less warehouse space, a smaller quantity of forklifts and superfluous spaces. Once the workflow is free of disturbances, materials taking up space, re-work and of inefficient relooping, waste can be abolished - but more importantly, to be lean is to strive for endless improvement in all areas of work (Liker 2004). So as to improve the work of the die-press and decrease waste, Shigeo Shingo taught his workers the TPS principles, and requested that the workers think. He dared them to be pioneers, and to find ways to quicken the process as a whole by abolishing unnecessary activities. The workers who worked the press and changed the dye operated as a team and collectively overcame obstacles and pursued development. It was the hands-on workers, who were working on-site, and who had more valuable opinions, experience, and expertise than those who do not work hands-on, who experimented, observed the data, and learned from the actualities (Liker 2004).

Lean Management comprises this system of improving the work process by those executing the work hands-on. The example of Shingo asking the team to think, to test, and to learn from the data, is the model of lean management. This idea was rapidly copied by Honda and other Japanese corporations and has now evolved into the world-class standard in manufacturing and in management systems in all types of work environments. While lean management principles have been compared to some natural mechanism such as stigmergy (Khaddaj et al. 2016), this paper discusses how the evolution of Lean Management relates to evolutionary design in nature.

Evolutionary design in nature and Lean Management Principles are two independent systems. The first describes the mechanisms of change; whereas, the second describes principles that could be applied in processes, products, and collaborative activities. Although the two are separate systems, there are synergies that go beyond their basic definitions. But to what extent is the Lean Management System a natural evolution and optimization construction management, as compared to the natural evolutionary mechanisms in nature? What can evolution and optimization in nature tell us about the implementation of Lean principles? Before developing the answers, it is necessary to study the established ideas of both systems in the circles of academics and researchers. 


\section{METHODOLOGY}

The objective of this paper is to derive a correlation between two seemingly independent concepts: Lean and evolutionary design in nature. In order to achieve the objective of this research, the following method was devised and followed: 1) define and understand evolution in nature and Lean as two independent dynamic systems 2) compare and contrast the two mechanisms 3) deduce the correlations 4) present the practical implications of the correlation.

\section{LEAN PHILOSOPHY}

Lean Management can be most completely understood as a way of life rather than a specific technique or method. Lean philosophy, attitudes, and culture can be summarized the fourteen principles of TPS that are to be mentioned in Figure 2, and may be described in the following set of statements.

Lean Management is a philosophy that aims at constant improvement practiced at all levels of the organization and by every team and team member, through studying work processes and systems and applying scientific methods of experimentation. Moreover, it is about respecting people, customers' needs, and those who do the work hands-on, who have more valuable opinions, experience, and expertise. Lean is the endless pursuit after removing waste in all its different forms, the capability to differentiate between work that adds value to the system and work that does not. It works towards having a work setting that guarantees the quality and safety of the work taking place for both the clients and the staff. It is focused on improving the process of work and not on blaming people or building fear and is a philosophy of teamwork, shared responsibility, and ownership that cuts through organization the many wasteful levels of bureaucracy. There are three pleasures of buying, selling and making the product. In relation, lean is a lifestyle that brings back the joy to work, and with this, the best work is produced. Lean is flow; it is, as much as possible, a disturbance free process that flows from start to finish without interruptions (Liker 2004).

\section{EVOLUTIONARY DESIGN IN NATURE}

Evolutionary design implies design modifications through time. The answer for the phenomenon of this design is explained through the Constructal Law accredited to Adrian Bejan. The Constructal Law states that flow systems should progress and optimize over time such that they provide better and easier access to the currents flowing through them. Constructal theory provides a broad coverage of "design" everywhere, from engineering to geography, biology, social sciences, animal design, technology and social organizations. So flow systems are everywhere, and they are governed by two properties: The current that flows (fluid, heat, mass, services, people, etc.) and the design through which this current flows. These properties are outlined in Figure 1. Flow systems exist with purpose, and once one realizes what is flowing through a system, one can think more clearly of what shape, structure, design, configuration, rhythm or architecture should emerge in order to help facilitate that flow. The design evolves over time to make flow easier, to make better designs, to increase flow access, to better achieve its purpose, to be more efficient, to 
enhance performance, and to offer greater and faster access to movement - this is what Bejan calls Constructal Law flows. This Constructal Law governs any system, anytime, anywhere and at every scale. It targets the inanimate such as rivers and lightning bolts, the animate such humans, trees, and animals, technological design such as cars, ships, and engines among others, and cultural concepts such as knowledge and language (Bejan 2016).

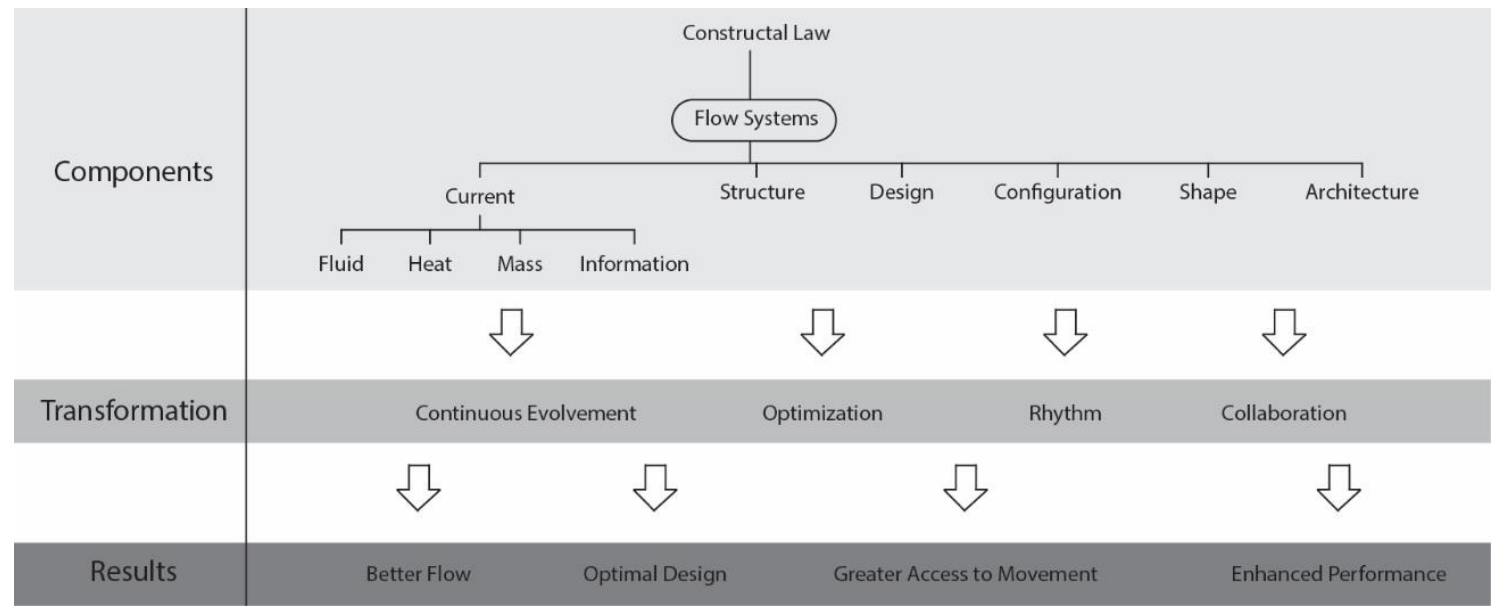

Figure 1: Constructal Law in nature.

Evolutionary design in nature is explained through the Constructal Law. The Constructal Law explains how the flow system generates its configuration in time and what mechanisms mark this flow system. For example, in evolution of sports, the mechanism of doing so is training, recruitment, mentoring, selection and rewards (Bejan and Lorente 2013). The phenomenon of evolutionary design is a global phenomenon. It is a naturally occurring phenomenon that is based on the Constructal Law, thus it is predicted and not descriptive and is apparent to the human senses. The design generation and evolution are macroscopic free movements that can be named: organization, configuration, architecture and change. The flow of this design runs in such a way that the existing pattern and organization are replaced by easier flowing configurations (Bejan 2016).

For example, the emergence and evolution of river basins shows that they are naturally and continuously replaced by forms that flow more smoothly. A river basin evolution produces an architecture (tree-like structure) that moves water (current) from the plain (area) to the river mouth (point). Over time, the river basins exhibit the hierarchical flow of large channels together with many small channels. Thus, it calls for a design with maximum flow access and optimal configuration. Treelike structures can be found as well in the air passage in lungs (a flow system for oxygen), the passage of electricity in the lightning bolt (a flow of electricity) and the transportation routes (a flow system for moving people and goods). Although tree-like structures are very common in nature, they are not the only manifestation of the Constructal Law. In addition to rivers, human beings are part of other, much larger, flow systems on Earth. When one gets into his car, he enters the flow of traffic. When one goes to work, he enters the flow of work related information. All these flow systems are morphing and evolving to facilitate the human movement; thus serving a much bigger picture: enhancing the global flow (Bejan 2016). 
Constructal Law provides us with a perspective about the concept of evolution and the direction of these evolutionary changes with time. The continuous evolution of everything is never out of control. Plotting the history of the covered territory against time shows an S-shaped curve. Every spreading flow has an S-shaped history of growth. It starts with an initial slow growth, followed by a much faster growth and a slow growth again.

Global optimization, rhythm and renewal, adaptation to nature or one's surroundings, collaboration and optimism are key features of evolutionary design. All of these are explained by the Constructal Law. Global optimization is observed through attaining the optimal structure, shape, design, configuration or architecture. This is not achieved by chance, but through continuous improvements for better performance and better results over time. Optimization is about choosing between the different alternatives that arise within the framework of set of constraints and resistance. It is based on the freedom to make the decision and replace the old existing configuration with a new configuration after a certain change has been done. The new configuration and as observed in most aspects is a more superior alternative in comparison to the older version, as observed for example in car manufacturing. Global optimization is a purpose driven process. It emerges after one is able to understand and realize the architecture of how the parts flow together; thus predicting the design and performance of the whole (Bejan 2016).

Rhythm is one of the features of evolutionary design. Everything in nature, from rivers to lungs, flows in patterns and rhythms. The pattern of evolutionary design follows a rhythm of continuous improvement. The mechanisms by which the flow systems achieve their goal mark the rhythm of the Constructal Law. The natural design is in the rhythm of systems, as it governs respiration, discretion, blood circulation, and other periodic body functions (Bejan 2016).

Collaboration is another feature of evolutionary design. Collaboration comes from labor, which means work, and work requires movement. In collaborating, entities are free to move, develop, change and find superior ways of flowing. Collaboration aims to help individuals flow together. Collaboration is a form of movement. It enhances the individual and the overall performance of the entities (Bejan 2016).

Evolutionary design has an optimistic vision towards life. Life is a universal tendency in nature. The positive outlook towards life goes hand in hand with making choices of purpose. When flow and movement stop, life ends. For example, when the current of information, materials and products stop flowing in a business, business would stop; thus reaching a dead end. When the configuration does not have the freedom to evolve and find better flow designs, the flow system stops. Evolutionary design never ends. The goal was and will always to be towards more life, better efficiency, greater movement, more access, increased flow, more freedom, longer life, greater wealth, and shorter paths (Dodds et al. 2015).

\section{THE RELATION BETWEEN LEAN AND EVOLUTION IN NATURE AND PRACTICAL FINDINGS}

Lean Production is based on the Toyota production system (TPS), which has emerged from unplanned results of separate enhancements (Fujimoto and Miller 2007) through following 
inductive methods to improve production systems. This subscribes to Aristotelianism (or Empiricism); an epistemology started by Aristotle (384 -322 BCE), who believed that scientific knowledge is based on perception (Lauri Koskela et al. 2019). According to Koskela 2019, lean production (including lean construction) falls within Aristotelian Epistemology, whereby empirical reality has been used while following effective methods to extract knowledge completing the knowledge cycle that starts with deductive reasoning as stipulated by Platonism.

Going further with Aristotelian Epistemology, comparing lean to evolution in nature and trying to find their mutual constituents is a way for observing relations between them and seeking explanation which can be applied to particular cases, and then generalized to explain new observations.

Defining Lean principles and evolutionary design in nature each as a dynamic system allows their comparison. The two systems have common constituents and environments that interact dynamically with each other. Based on this initial relation between Lean and evolutionary design in nature, we will additionally relate the two based on their definition, features and through examples.

Despite being seemingly different concepts, Lean and evolutionary design in nature are comparable. It was deduced that the two systems are related and that evolution in nature can describe and justify the formation and use of Lean in the construction industry today. We will discuss how Lean and evolutionary design in nature are related through a few examples as categorized by definition, features and examples.

\section{IN TERMS OF DEFINITIONS:}

The phenomenon of evolutionary organization facilitates accessing everything that flows, evolves, spreads and is collected: technology, atmospheric and ocean currents, river basins, animal life and migration, besides other systems that fit within the evolution of the human and machine species, wealth and everything else that encompasses human life (Bejan 2016). In relation, lean principles aim to create "process" flow, and continuous improvement and development, which are related to evolution in nature as shown when river basins are ever changing to find optimum routes, or when migration patterns are optimized for shortest duration.

\section{IN TERMS OF FEATURES AND EXAMPLES:}

Lean applies the concept of standardizing tasks for continuous improvement - for example, the Lungs are the best organs at what they do because they do so consistently and do not change their function, the same can be said in lean - when each worker is assigned a standardized task, he will perform it better than a worker who works haphazardly. Lean principles linked to features and examples from nature may be summarized in Figure 2. 


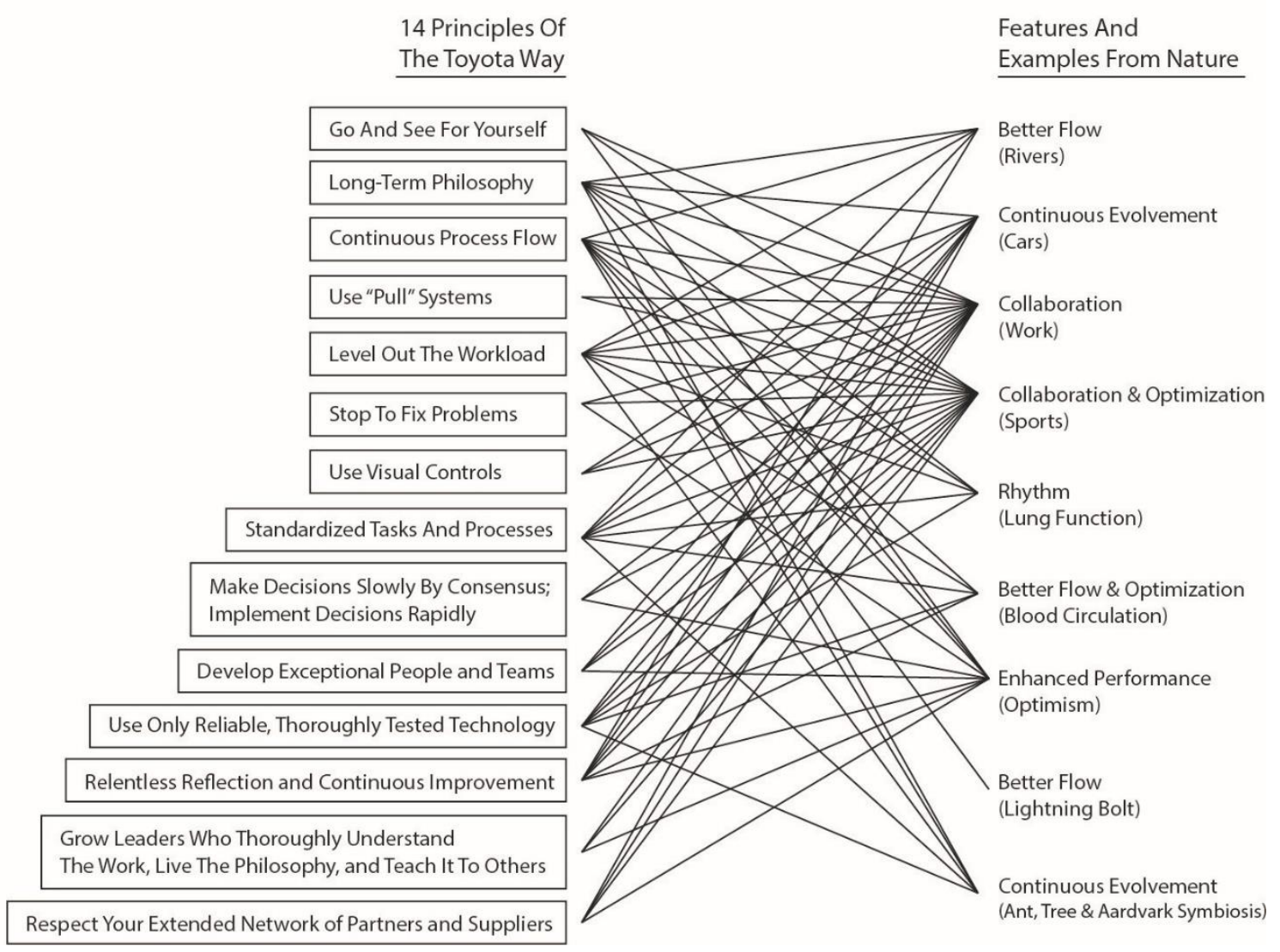

Figure 2: Lean principles as compared with features and examples from nature.

Optimism also goes hand in hand with making choices of purpose and can be found in nature in the will to survive, and in Lean in the principles of continuous development. Lean identifies one of its principles as identifying value and purpose in the eye of the customer - this is similar to natural selection in nature which identifies dominant and more resistant, or valuable, genes, as opposed to the recessive or one with less value in terms of survival. Optimization is attained by making changes and deciding between different options. To opt means to make a choice - or to have the ability to choose. Freedom of decision and capability to enhance, change, and develop the existing design define the major approaches toward change. Then comes the decision to choose between the alternatives that develop after the change. "To opt is not a one-punch boxing match. It is a relentless fight, because to find better choices after a change is good" (Bejan 2016).

Collaboration as found in nature is related to the Lean principles of seeing for oneself, developing exceptional people and teams, relentless reflection and continuous improvement among others. Examples in evolutionary design include the development of cars, and philosophies which govern sports. Another example found in nature is that of the symbiosis of the ants, trees, aardvarks, and river basins. Initially, a mound is full of termites. Aardvarks then dig around the mound and destroy it in order to reach the termites. However, the termites rebuild their galleries again. The target behind this three-way symbiosis is so that the fourth, most important member, the circuit of water, can benefit and flourish as a 
result of the ever-changing mound architecture. Just like lean, all of these factors are necessary. Without the water flow, the ants, trees and aardvarks would die - this relates directly to the lean principle of long term thinking and looking at the big picture. Without the first three, the water flow dies locally and moves to another mound, another nursery system - which is seen in lean in the form of bottlenecks, and that if the problem is not dealt with accordingly and at the source, bottlenecks will transfer from one area to another and persist. This example happens naturally without any interference; it always aims towards ease of flow in nature which relates directly to the Lean principles of continuous self-reflection, self-improvement, and continuous process flow.

Rhythm as found in nature is related to the lean principles of continuous process flow, levelling out the workload, standardizing tasks and processes, and in using only reliable technologies among others. Examples in nature include the functioning of the lungs and blood flow - each of which operate rhythmically and are assigned standardized tasks to undertake.

Continuous Evolvement as found in nature is related to the lean principles of relentless self-reflection and continuous self-improvement. Examples from nature include the flow of river basins which flow until they are at their optimum shape, in the migration patterns of birds which evolve to reach the shortest, most efficient route, and in the development of cars and ships which are continuously evolving to give the client maximum value.

Lean construction came as a new alternative for construction projects. It is a choice that is based on complete freedom. Lean principles demand continual organizational learning. Lean is the current "best" alternative, in the future, it may continuously improve to morph into another superior "best" concept.

\section{CONCLUSIONS AND RECOMMENDATIONS}

This paper explores synergies between the two seemingly distinct concepts of evolutionary design in nature and Lean management principles. This is performed by studying each notion on its own through breaking it down to its dynamic functional systems, and comparing the functions of each against one another. Findings reveal that the development of lean since its inception is comparable to the natural mechanisms of evolutionary design in nature.

Evolutionary design evolves over time to make flow easier, to make better designs, to increase flow access, to enhance performance and offer greater access to movement. Lean, on the other hand, represents a philosophy based on a long term thinking. Lean principles aim at optimizing the whole and not the parts to produce the desired value needed by the customer. This paper discusses how the two independent systems are related to one another. The division of each concept into its elements or principles help us realize that Lean is the natural evolution of construction management through relating it to evolutionary design in nature. The mere realization of the natural evolution of construction management into Lean can cast Lean in a new light, lend the system as more credible, and become conscious of construction system's continuous development and progress. Through the examples and figures provided, this paper shows how similarities exist between Lean and evolutionary design in nature both in theory and in execution. Timeless principles in Lean such as 
constant improvement, respect, removal of waste, quality and safety, not blaming people or building fear, teamwork, shared responsibility, flow, and positivity will always be present in future advancements of lean construction systems and methods.

Future research can possibly observe what nature's age-old wisdom can teach us, and see how we can apply its principles in advancing Lean. Further research may also consider further comparisons between evolutionary design and lean management.

\section{REFERENCES}

Bejan, A., (2016). The Physics of Life: The Evolution of Everything. New York: St. Martins Press.

Bejan, A. and Lorente, S., (2013) "Constructal Law of Design and Evolution: Physics, Biology, Technology, and Society," Journal of Applied Physics 113: 151301; Bejan, A., Entropy Generation through Heat and Fluid Flow (New York: Wiley, 1982), viii.

Dodds et al., P. S. (2015) "Human Language Reveals a Universal Positivity Bias," PNAS 112, no. 8: 2389-2394.

Einstein, A. and Infeld, L. (1938) The Evolution of Physics (New York: Simon and Schuster, 291.

Fujimoto, T., and B. Miller. 2007. Vol. 22 of Competing to be really, really good: The behind-the-scenes drama of capability-building competition in the automobile industry. Tokyo: International House of Japan.

Howell, G. A. (1999). What Is Lean Construction. International Group for Lean Construction (IGLC-7). Berkeley, California, USA.

Khaddaj, M.B., Kachouh, H., Halaby, B. and Hamzeh, F.R. (2016). "Lean Management Principles and Stigmergy." In: Proc. 24th Ann. Conf. of the Int'l. Group for Lean Construction, Boston, MA, USA, sect.7, pp. 23-32

Koskela, L., Ferrantelli, A., Niiranen, J., Pikas, E., \& Dave, B. (2019). Epistemological Explanation of Lean Construction. Journal of Construction Engineering and Management, 145(2), 04018131.

Kwak, Y. H. (2003). Brief History of Project Management. In E. G. Carayannis, Y. H. Kwak, and F. T. Anbari, The Story of Managing Projects. Quorum Books.

Liker, J.K. (2004). The Toyota Way- 14 Management Principles from the World's Greatest Manufacturer. New York: McGraw Hill.

Symour, T., and Hussein, S. (2014). The History of Project Management. International Journal of Management and Information Systems, 223-240. 